Article

\title{
Can Machines Be Artists? A Deweyan Response in Theory and Practice
}

\author{
Arthur Still ${ }^{1}$ and Mark d'Inverno ${ }^{2, *(1)}$ \\ 1 Department of Psychology, University of Durham, Durham DH1 3LE, UK; stillarthur65@gmail.com \\ 2 Department of Computing, Goldsmiths, University of London, London SE14 6NW, UK \\ * Correspondence: dinverno@gold.ac.uk
}

Received: 9 January 2019; Accepted: 7 March 2019; Published: 19 March 2019

\begin{abstract}
To speak comfortably of the machine artist (as outlined in the call for papers for this Special Issue) makes key assumptions about what it is to be an artist. It assumes, for instance, that the experience of living as an artist, which includes the socialisation, hard work, single-mindedness, and focused energy of creative activity, is incidental rather than essential since these aspects are not comfortably applicable to machines. Instead, it supposes that what is essential is the artistic product, and it is the similarity of human and machine products that makes it possible to speak of machine artists. This definition of art in terms of products is supported by modern psychological theories of creativity, defined as the generation of novel ideas which give rise to valuable products. These ideas take place in the mind or brain, regarded as a closed system within whose workings the secret of creativity will eventually be revealed. This is the framework of what is widely referred to as "cognitivism". This definition in terms of novel ideas and valuable products has been widely assumed by artificial intelligence (AI) and computational creativity (CC), and this has been backed up through a particular version of the Turing Test. In this, a machine can be said to be a creative artist if its products cannot be distinguished from human art. However, there is another psychological view of creativity, that of John Dewey, in which a lived experience of inquiry and focus is essential to being creative. In this theory, creativity is a function of the whole person interacting with the world, rather than originating in the brain. This makes creativity a Process rather than a Cognitivist framework. Of course, the brain is crucial in a Process theory, but as part of an open system which includes both body and environment. Developments in "machine art" have been seen as spectacular and are widely publicised. But there may be a danger that these will distract from what we take to be the most exciting prospect of all. This is the contribution of computer technology to stimulate, challenge, and provoke artistic practice of all forms.
\end{abstract}

Keywords: creativity; art; art practice; AI; designing AI; John Dewey

\section{Introduction}

According to the call for papers for this Special Issue, the time has come when we can speak comfortably of the machine as artist. This reflects a measure of the great successes in over 60 years of work on creativity in artificial intelligence (AI) and psychology. In these disciplines, the issue of creativity in the arts, science, and everyday life has been a dominant theme since 1950, and it has been widely accepted that the essence of creativity has to do with having novel ideas in the mind or brain, which give rise to creative products. These inner processes are the focus of investigation in both cognitive psychology and AI, but it is the quality of the product that defines creativity. This focus on products and ideas is a widely held view, and it has been behind the development of the field of computational creativity (CC). This is the attempt to design machines which produce artefacts regarded as creative. It is the success in this that makes it seem appropriate to refer to such machines as artists. 
But what if what we mean by "art" and "artist" is not just the making of novel products that are regarded as creative, but the way of life that accompanies this making, including the long training and socialization, and the sheer slog of preparation and effort that culminates in becoming an artist? The experience, in other words, of living and working as an artist. In the biographies of artists, much is made of this. Ideas play a part, as they do in most human activities, but it is the life and the artistic and cultural context of the artist that are distinctive in understanding the genesis of artistic work. This we take to be the view of John Dewey, and in this paper, we explore the implications of taking a Deweyan view to the idea of the machine as an artist.

We start the paper by spelling out more fully the first view, that the essential meaning of art (or science) lies in the creative products generated by art or science. This is the view that follows from a common and influential definition of "creativity" itself. We then set out a contrasting perspective by outlining our version of Dewey, updated to consider modern developments in AI and CC. We end with a discussion section and by outlining some systems which implement a Deweyan approach to using $\mathrm{AI}$ in the context of creativity.

\section{Creativity in Psychology and AI: Computational Creativity}

In 1950, the Psychologist J.P. Guilford gave the presidential address to the American Psychological Association, with the title "Creativity", thereby making use of a word that had been rare before the 20th century but had recently become popular in marketing circles. In this dramatic way, he introduced "creativity" to psychologists as a measurable process in the individual mind. Guilford defined the word by explaining that "the creative person has novel ideas" and "creativity refers to the abilities that are most characteristic of creative people." (Guilford 1950, p. 452).

Two other criteria were soon added-to be creative the novel ideas must be put into practice, and the products must be valuable (Stein 1953). This brought it in line with the marketing use of the word "creativity", spelled out two years before Guilford's address by the marketing executive and self-help guru, Osborn (1948), inventor of "brainstorming".

From its modern beginning in 1950, work on creativity has undergone a parallel evolution in two disciplines-cognitive psychology and artificial intelligence (AI). In both disciplines, creativity has been praised more than is usual in a scientific concept. Margaret Boden, the philosopher of AI who is also a psychologist, described creativity as "a marvel of the human mind" (Boden 2009, p. 23) and went on to define it as

the ability to generate novel, and valuable, ideas. Valuable, here, has many meanings: interesting, useful, beautiful, simple, richly complex, and so on. Ideas covers many meanings too: not only ideas as such (concepts, theories, interpretations, stories), but also artefacts such as graphic images, sculptures, houses, and jet engines. (Boden 2009, p. 24)

A similar high valuation is expressed by the psychologists Beth Hennessey and Teresa Amabile, in a recent major review. They write that

If we are to make real strides in boosting the creativity of scientists, mathematicians, artists, and all upon whom civilization depends, we must arrive at a far more detailed understanding of the creative process, its antecedents, and its inhibitors. The study of creativity must be seen as a basic necessity. (Hennessey and Amabile 2010, p. 570)

They go on to define it as "the development of a novel product, idea, or problem solution that is of value to the individual and/or the larger social group" (Hennessey and Amabile 2010, p. 572). For these writers, civilization itself has arisen naturally through unaided creativity by gifted individuals, but now the demands for progress and national achievement are greater, and scientific psychology and theoretical understanding are required to help it along. 


\section{Some Reservations about These Definitions}

However, doubts have been raised about these definitions of creativity in terms of novel ideas. An early warning came from Theodor Levitt, a leading marketing academic at Harvard Business School in the 1960s. He argued that what is important in modern American creativity is innovation, and that creative ideas themselves are relatively trivial:

The fact that you can put a dozen inexperienced people into a room and conduct a brainstorming session that produces exciting new ideas shows how little relative importance ideas themselves actually have. Almost anybody with the intelligence of the average businessman can produce them, given a halfway decent environment and stimulus. The scarce people are those who have the know-how, energy, daring, and staying power to implement ideas. (Levitt 1963)

These human attributes conventionally belong to innovators in any field. They are not inner processes in the brain but refer to activities in the social world over long periods of time, and certainly apply to the innovating computer scientists responsible for the achievements of CC. However, they cannot comfortably be applied to computers or programmes themselves; if this is the case, it is not the computers of CC which have these qualities and are creative, but the computer scientists who build them and write their programmes. More generally, if these qualities are among the distinctive characteristics of being an artist, it would be misleading to speak of the machine as an artist.

Furthermore, in many of the world's artworks, it is not novelty that is achieved and admired, but ambition in scope and perfection in execution. This is true, for instance, of much medieval art, such as illuminated manuscripts and the great medieval cathedrals; it is also true of classical Eastern art, including dance and theatre. It is the sheer beauty and manifest skill that counts. Michelangelo was admired by his contemporaries above all other artists; not because he had novel ideas, which he undoubtedly did like many others, but because of his unique skill and the energy and persistence with which he practiced them.

Some of these limitations were acknowledged early on by a few of the many writers on creativity and the meaning of creativity has been extended to include such interactive art as dance and jazz, and social factors (and not just individual brains) are now being given full weight in psychology (Glăveanu 2010). The result is that, although the definition of creativity in terms of novel ideas remains, the implementation side has been much expanded, as in the definitions given above by Boden (2009) and Hennessey and Amabile (2010). This is even clearer in a definition given in 2018 by Michael Mumford

Creativity is not simply a matter of generating ideas. Instead, creativity is defined as the production of high quality, original, and elegant solutions to complex, novel, ill-defined problems. ${ }^{1}$

In this definition, although creativity may involve generating ideas, more goes on in the mind and the world than the simple generation of novel ideas and valuable products envisaged by earlier writers. This more general picture by Mumford is part of how we judge creativity. Colton makes a similar point on behalf of CC when he writes that the product alone is not enough in assessing creativity and in the case of painting "the process of creating an artefact is often a deciding factor in the assessment of that artefact." (Colton 2008). In practice, CC is by no means only a search for a creative product but has widespread applications to other fields, such as education and medical diagnosis (Wagstaff 2012; Sturm and Ben-Tal 2017).

1 From the abstract of his paper "Creative Thinking Processes: The Importance of Strategies and Expertise" given at the Southern Illinois Creativity Conference, 2018. 
Nevertheless, in spite of these reservations, the word "creativity" itself, which seems equally at home in scientific psychology, CC, marketing, and popular use, does seem to be held together by a common emphasis on novel and valuable products. The general theory behind this is that the implementation of the inner processes in the brain gives rise to great products (from nuclear weapons to space rockets as well as the works of Shakespeare, Michelangelo, and Mozart, and commercially successful products like fish fingers, jeans, and Facebook). But as it developed in psychology, the theory has become more democratic, and most writers insist that similar inner processes go on in ordinary people, and give rise to products that are novel and valuable to them, even if to no one else.

Given this general theory, the scientist's task is to discover the mechanisms that generate such novel and valuable products. As Herb Simon, himself a Nobel prize winner put it:

The notion that creativity requires inspiration derives from puzzlement about how a mechanism (even a biological mechanism like the brain), if it proceeds in its lawful, mechanistic way, can ever produce novelty ... for novelty is at the core of creativity. In fact, we shall define creativity operationally, in full accordance with general usage, as novelty that is regarded as having interest or value (economic, aesthetic, moral, scientific or other value). (Simon 1995, p. 945)

On this way of thinking, it is the brain that is seen as the mysterious (but mechanistic) source of creative products, which is the stance taken by many cognitive scientists who are investigating creativity. As Guilford himself wrote years before he discovered the word, "all the results of human invention and construction are creations of the human brain" (Guilford 1939, p. 486).

If, as is widely believed, brains are like computers, the way is open to treating computers as a model for investigating the brain's creative processes. To do this, it is necessary to evaluate the computer's power of creativity by measuring the creative value of its products. This has often involved applying a version of the Turing test of machine intelligence, but to artificial creativity rather than to artificial intelligence.

In the same year as Guilford's "Creativity", Turing published his famous paper "Computing machinery and intelligence" in which he set out a test of whether or not computers can be said to think, and a variation on this test has been widely used to evaluate whether computers can be creative. Since thinking was regarded by Turing as a process that takes place in the mind or brain, his test "has the advantage of drawing a fairly sharp line between the physical and intellectual capacities of a man" (Turing 1950, p. 455). He suggests that chess would be an appealing way (Turing 1950, p. 460) of testing the intellectual powers of machines, but his own test of thinking in what he called the imitation game is more searching. In this game, an investigator asks questions of both a machine and a human to determine which is which. The machine's task is to mislead the investigator into thinking that it is human and its success in this is taken to indicate that it is intelligent and can think.

Towards the end of the paper, he touches on creativity by introducing Lady Lovelace, the Nineteenth-century thinker whose reflections on computing machines anticipated some of the modern discussion in CC. She was the first to raise a key question for CC-whether the output of a machine could really surprise us. In her answer, she asserted, in Turing's paraphrase, that a machine can only do what we tell it to (Turing 1950, p. 454; Boden 1990).

A version of the Turing test has been used to test a machine's artistic creativity. If computers can produce works of art, music, or literature that cannot readily be distinguished from human products, then they can be said to be creative or to create. This test is very much simpler than the original and has been criticized on these grounds (Ariza 2009). The original involved probing questions from the investigator, and crafted answers from the machine, whereas this version is only a simple discrimination. Nevertheless, it has been widely used and referred to as a "Turing" test.

Probably the most famous of the early exercises in computer creativity is Harold Cohen's AARON which has been producing pictures since 1973. These can be in a variety of styles, but the choice of style is set by the programmer. Unlike a human artist, it does not learn about styles by looking at 
pictures or talking to other artists. A few years later, David Cope began work on programmes that compose music and published a CD in collaboration with "Emily Powell", a computer programme sometimes known as EMMY. As with AARON, styles are set by the programmer rather than through investigation and learning. Both AARON and EMMY have produced artworks that people have difficulty distinguishing from those of human artists or composers. They have therefore passed the Turing test (the non-interactive version) "at a world-class level" (Boden 2010). They are adamant that their systems are creative, though they might hesitate to call the computer itself a machine artist. After all, the artefacts depend on the programmer's instructions, and there is little about the inner processes that parallel the human artist, as their critics have pointed out (Wiggins 2008). They may occasionally surprise us, but only as a consequence doing what they are told, so they do not strictly refute Ada Lovelace's assertion that machines, "can only do what they are ordered to do" (Turing 1950, p. 454) They are similar in this respect to the well-publicized exploits of Deep Blue, the chess playing system that defeated Gary Kasparov, the world champion, in 1997. To paraphrase Lady Lovelace again, Deep Blue may have sometimes surprised Kasparov, but it was only doing what it was told to do.

This is because Deep Blue depended on what Gary Kasparov himself called "brute force": "Instead of a computer that thought and played chess like a human, with human creativity and intuition, they got one that played like a machine, systematically evaluating 200 million possible moves on the chess board per second and winning with brute number-crunching force" (Kasparov 2010). Like AARON and EMMY, it lacked independence from the programmer and was not autonomous and creative in its own right.

But the science of $C C$ has moved on dramatically in the last 20 years, with the use of developments in statistical methods of neural networking applied to pattern recognition and learning This has made possible techniques such as style transfer, and GAN (generative adversarial networks).

In style transfer, using a form of cluster analysis, a machine extracts a common style from a set of images and imposes this style on another image. In an example widely familiar to Google searchers, Hokusai's "The Wave" ("The Great Wave off Kanagawa") is impressively reimaged in the style of Van Gogh.

GAN is a technique for rapid unsupervised learning on the part of a computer confronted by a set of images to be analysed for clusters or patterns. The programme is divided into two neural networks. One (the artist we might say) extracts patterns in the data and generates images from these. The other (the critic) compares these trial images with the originals and feeds back discrepancies to the artist. The artist then carries out another trial incorporating these discrepancies, the critic criticizes, and so on. The learning is rapid, with a structure that is identical to the original use of the phrase trial and error as a quick way of homing in on a target in gunnery practice (Hutton 1811).

GAN has been widely acclaimed as a model of imagination, and Eigemmal et al. (2017) has changed the acronym to CAN (creative adversarial networks), in a paper in which he used a classic psychological model of aesthetic appreciation based on arousal level. The critic network uses this to feedback evaluations to the artist. This has led to the development of AICAN, "an almost autonomous artist" (Mazzone and Eigemmal 2019).

GAN has had several well-publicized successes. It was used in the generation of the portrait Edmond de Belamy which fetched \$432,550 at Christies in 2018, and in the development of AlphaZero, which rapidly learns a variety of games, including Chess, to a world-class level (Silver et al. 2018). In chess, it homes in on the best move through a process that seems more like human thinking than the brute force of Deep Blue. Kasparov himself has changed his mind about computers and finds creativity in the "deep thought" shown by AlphaZero (Kasparov 2018).

With such results, the idea of a machine artist is becoming commonplace. As Simon Colton, writing of his own creation The Painting Fool, puts it, "it is our hope that one day people will have to admit that the Painting Fool is creative because they can no longer think of a good reason why it is not." (Colton 2012, p. 36). 


\section{Dewey's Creativity}

Now, we risk spoiling the party by introducing another American, John Dewey (1859-1952), whose theory of creative activity and definition of creativity are not just an alternative to Guilford, AI, and CC, but close to its antithesis, since its emphasis is on experience rather than products. It is not that Dewey (as we imagine) would be hostile to either AI or CC, but he would warn against confusing the two aims that are embedded in these fields. The first is to carry out tasks that would normally be carried out by humans, and the second to throw light on the nature of human creative activity. Just to be clear, our Dewey-based criticism of AI and CC is not about the first, but only the second. Obviously, it is not Dewey himself (he died in 1952), but our imagined Deweyan response.

John Dewey's definition of creativity appeared in 1948, two years before that of Guilford. Its publication passed unnoticed and has been largely ignored, although many of Dewey's own ideas on education have been assimilated into work on creative activity in schools (Johnston 2006). For Dewey, there is nothing marvellous or even extraordinary about creative activity. It is the natural state of being. But it is easily suppressed by teaching that is dominated by a curriculum that demands the learning of facts and theories in science and the arts at the expense of individual and group inquiry. As the humanist psychologist Abraham Maslow wrote:

The key question isn't “What fosters creativity?" But why in God's name isn't everyone creative? Where was the human potential lost? How was it crippled? I think therefore a good question might not be why do people create? But why do people not create or innovate? We have got to abandon that sense of amazement in the face of creativity, as if it were a miracle that anybody created anything. (Maslow [1959] 2000, p. 185)

John Dewey is often regarded as America's greatest philosopher and was equally influential as an educationalist and as a psychologist. In addition, his work on thinking and inquiry formed the basis of his monumental work on artistic activity, Art and Experience (Dewey 1934), as well as investigations of scientific thinking. His aim in education was to move away from what regarded as the stultifying effect of learning facts and rules and towards the cultivation of habits of free inquiry and critical thinking (Rudolph 2014). The word "creative" was important in his own thinking about science, the arts, and human living in general. This emphasis on free inquiry put him at odds with standard practice in education and psychology, with its emphasis on intelligence as a fixed power in the mind. He did not like the practice of measuring human minds or the uses to which measurement was put. He did not write at length about this, but in 1917 he edited a book containing contributions from like-minded pragmatist philosophers and psychologists, notably his close friend and colleague G.H. Mead.

At that time, the measurement of intelligence was coming to the fore, first in the service of eugenics and then as a way of filtering out the mentally unfit and potential officers during World War I (Mackintosh 2011). For these purposes, the creative aspects of the Binet tests were left out (as Guilford 1950, acknowledges), and this formed the basis of the arid measure of intelligence known as IQ, as well as, much later, the concept of intelligence in "artificial intelligence". For Dewey, by contrast, thinking and intelligence both involve inquiry and are creative by their very nature. This difference is pointedly captured in 1917 by the title of his edited book, Creative Intelligence.

In using the word "creative", Dewey was drawing on an important tradition. At the time, the word was commonly used to qualify "imagination" as in Ribot's Creative Imagination (Ribot 1906). This referred to the imagination involved in creative activities like art, but it was also used more generally to refer to the activity itself. Wordsworth used it in this way when he referred to the joys of "creative agency" meaning the exhilarating focus of energy involved in all aspects of writing. This usage was taken up by later Nineteenth Century writers familiar with Wordsworth, such as Emerson's "creative reading" (Emerson 1975) and Matthew Arnold's "creative criticism" (Arnold 1914), where the word refers to the activity itself and the experience of focused energy that goes with it, irrespective of any product. 


\section{Whitehead's Creativity}

Dewey knew Wordsworth's poetry well and wrote on both Emerson and Arnold. Drawing on them, his ideas about free inquiry and creative activity were worked out by 1920, but his later use of "creativity" derives from the use of the word by Alfred North Whitehead. During the 1920s, and independently of Dewey's use of "creative", the logician and philosopher introduced the word "creativity" as an inherent property of variation and change in a universe that is not mechanical in the Newtonian sense:

In the abstract language here adopted for metaphysical statement, "passing on" becomes "creativity," in the dictionary sense of the verb create, "to bring forth, beget, produce." [and] no entity can be divorced from the notion of creativity. (Whitehead [1929] 1968, p. 213)

Dewey and Mead discussed Whitehead at length (Cook 1979), and later Dewey introduced the word "creativity" in his own writings. This described an individual process of change to correspond to Whitehead's more general process of change in the universe, and it reflected his own earlier use of "creative".

\section{Dewey's Definition of Creativity}

So, when he defined creativity in 1948, he referred to experience, and a process of full involvement, focus, zest, and mindfulness. We give this little-known definition in full, beginning with his own use of "creativity" in 1942:

The emphasis James places upon the individual quality of human beings and all things is, of course, central in his pluralism. But the adjective "individual" is often converted into a noun, and then human beings and all objects and events are treated as if they were individual and nothing but individual. The result is that identification of human beings with something supposed to be completely isolated which is the curse of the so-called individualistic movement in economics, politics and psychology. I find the actual position of James to be well represented in a remark he quotes from a carpenter of his acquaintance: "There is very little difference between one man and another; but what there is, is very important." It is this element which is precious because it is that which nobody and nothing else can contribute, and which is the source of all creativity. Generic properties, on the other hand, are replaceable and express the routines of nature. (Dewey [1942] 1989, pp. 4-5)

Later, in a foreword to Schaeffer-Simmern (1948) The Unfolding of Artistic Activity, Dewey gave a definition of "creativity" in a paragraph which captures in a few words his theory of what it means to be creative. He defined creativity as

the life factor that varies from the previously given order, and that in varying transforms in some measure that from which it departs, even in the very act of receiving and using it. This creativity is the meaning of artistic activity-which is manifested not just in what are regarded as the fine arts, but in all forms of life that are not tied down to what is established by custom and convention. In re-creating them in its own way it brings refreshment, growth, and satisfying joy to one who participates.

Accompanying this principle ... is the evidence that artistic activity is an undivided union of factors, which, when separated, are called physical, emotional, intellectual, and practical-these last in the sense of doing and making. These last, however, are no more routine and dull than the emotional stir is raw excitation. Intelligence is the informing and formative factor throughout. It is manifested in that keen and lively participation of the sense organs in which they are truly organs of constructive imagination". (Dewey 1948, pp. ix-x)

Creative activity, therefore, is activity that has an impact by sustaining or changing the established order that has guided the individual to which she belongs; and is present in everyday activities, such as 
gardening or cooking, where there is a state of creative intelligence, active interest, and alertness. They are what Dewey called "habits of thinking" and if he ever read Guilford's 1950 paper his suggested correction would be simple: Instead of "the creative person has novel ideas", he would write "the creative person has the habits of thought that make for creative activity"; these habits of thought comprise habits of perseverance, patience, interest, curiosity, awareness, as well as those envisaged by Levitt.

He had already spelled this theory out in Art and Experience (though without using the word "creativity"), and he saw it in action in Schaeffer-Simmern's book, notably in the narrative with which the book begins. This is the story of Selma, a 30-year-old woman with an IQ of 49, who had been treated with great brutality until she arrived at the institution where she met Schaeffer-Simmern. At first, she was severely withdrawn and almost mute. The author describes how she was gradually encouraged to copy pictures, then to draw them in her own distinctive way, and went on to work with other women in the institution to produce a cooperative for herself. In this way, she discovered the possibility of a full life.

With this as a model, Dewey's way of bringing about a creative life that offers "refreshment, growth, and satisfying joy" would not be to train in creativity directly by encouraging novel ideas and self-expression. Instead, it would be to cultivate the habits of thought and imagination that point towards creative activity and militate against the blind following of "custom and convention". The classroom observations reported by Guy Claxton can serve here as a brief example of this approach (Claxton 2006).

A teacher, Louise, noticed that her year six pupils got reasonably good results by skimming over the surface of the learning. She found that her instruction to set them working ("Off you go!") sounded like a starting pistol in the heads of a large number of children, who immediately became competitors in a race to be the first to her desk with 'Miss, I've finished, what shall I do now?'. The habits of thought behind this classroom behaviour may make for a productive life in a competitive market, but it would not be a creative one, in Dewey's sense of creative. Accordingly, Louise attempted to change the habits of thought towards reflection and understanding, leading on to further inquiry without having to be instructed by the teacher. This change in the habits of thought was a joint effort initiated through discussions between teacher and students. As a result, Louise's

desire that they should learn the pleasure of taking time, digging in, asking questions and challenging themselves was being more effectively communicated to the children-and they were responding. (Claxton 2006, p. 61)

\section{Dewey's Brain}

This is the tradition drawn upon by Dewey, but it would be a mistake to dismiss Dewey's view of creative activity as literary or humanistic. Like William James, he was well aware of the scientific psychology of his time. He had a wide knowledge of philosophy, literature, and art, but the thrust of his thinking was towards a scientific account, and he aimed for one better than that offered by the classical atomistic theories dominant at the time. His clearest statement of this is his famous reflex arc paper of 1896. There he argued that behaviour is essentially a flow and cannot be reduced to the stimulus-response reflex, in which stimulus and response are distinct units, causally connected. Instead, "stimulus" points forward to "response", and "response" points back to "stimulus", each defined in terms of the other. This led to his holistic view, which gave the brain a different role from that imagined by Guilford and Herb Simon. For them, the brain is a relatively closed system, being separated from its environment by the senses regarded as transducers. For Dewey, the brain is part of an open system, and this system is not treated as mechanistic. Nevertheless, it is materialist, and ultimately physical-in this sense, it is similar to other open systems, such as Varela et al. (1991). As Dewey himself wrote:

An animal is... continuous with chemico-physical processes which, in living things, are so organised as really to constitute the activities of life with all their defining traits. And 
experience is not identical with brain action; it is the entire organic agent-patient in all its interaction with the environment, natural and social. The brain is primarily an organ of a certain kind of behaviour, not of knowing the world. (Dewey et al. 1917, p. 36)

It follows that thinking and intelligence for Dewey are processes that belong to the whole organism and are not confined to the brain or mind.

\section{Discussion}

How do we decide between these two traditions for thinking about creative activity? In the 70 years since modern "creativity" first appeared, with its standard definition connecting novel ideas with valuable products, the word has become so embedded in scientific, CC, marketing, and everyday usage that it is hard to think of a viewpoint like Dewey's being a serious scientific contender. Things may change, but for the time being, we find it helpful to think of it as a struggle for meanings around the word "creative", a struggle between the traditional dualist view of human beings, sometimes known as cognitivism or representational cognitivism (Still 1986), and the alternative represented here by Dewey, a form of process theory.

The cognitivist theory is clearly in charge at the moment. An interim result of the struggle is that the word "creativity" has changed its meaning in English. In the theories of Whitehead and Dewey, it was a group and individual process of change. But in cognitivism, represented by Guilford and AI, it has become an individual power of the mind or brain to generate novel and valuable ideas.

Of course, meanings change, often driven by technical innovation. As Paul Valery wrote, in a passage that forms the epigraph to Walter Benjamin's widely discussed essay on the impact on our notion of the art of reproduction through photography and film:

Our fine arts were developed, their types and uses were established, in times very different from the present, by men whose power of action upon things was insignificant in comparison with ours. But the amazing growth of our techniques, the adaptability and precision they have attained, the ideas and habits they are creating, make it a certainty that profound changes are impending in the ancient craft of the Beautiful. In all the arts there is a physical component which can no longer be considered or treated as it used to be, which cannot remain unaffected by our modern knowledge and power. For the last twenty years neither matter nor space nor time has been what it was from time immemorial. We must expect great innovations to transform the entire technique of the arts, thereby affecting artistic invention itself and perhaps even bringing about an amazing change in our very notion of art. (Valery, quoted in Benjamin [1937] 1968, p. 219)

In the essay itself, Benjamin pointed out that, considered as visual art forms, photography and film differ essentially from traditional museum art, where the individual artefact has an "aura" generated by its authenticity. Reproductions are far less valuable than the unique original since they lack the aura, but this doesn't apply to photography and film; in these new art forms what we see is always itself a reproduction, and the original can be reproduced indefinitely without loss of value. He argued that it is a mistake to try to assimilate these new forms to what went before, by forcing them into a fixed category or concept of "art". Instead, the western notion of art has changed, even though we may continue to use the same word. Photography and film have joined painting and sculpture as visual art, even though the aura is lost. The old art talk about meanings and intentions and creative influences will still be there.

Therefore, the change in meaning investigated by Benjamin leaves the artistic activity relatively intact. In photography and film, the product is different in form from that of traditional museum art, but the hard work and dedication and talk remain part of the life of the artist, even if the techniques and nature of the product have changed.

This is not true of machine art or machine as an artist. Here, the products are roughly the same, but the experience behind it is totally different. None at all in one case, the same old sweat and tears in 
the other. Does this warrant declaring a change of meaning, or can we (pace Benjamin) fit the machine into the old category of artist?

This is not a question of the quality of machine products. Shifting attention to Valery's word "beautiful", it is certainly possible that autonomous computers will produce sounds or words of an exquisite beauty that we cannot yet imagine, and that will be much sought after. And, of course, an artist will learn from this, just as chess players learn by practicing against chess programmes and tennis players may one day learn by playing with robot tennis players.

Machines may serve as a resource in many other ways. The future poet, for instance, might draw on the computer's vast database and speed of search, to produce rapidly a poem that shows a mastery of language and style well beyond the reach of most human poets. Welcoming this, the human poet will use the computer as a resource to train herself, like a chess player playing against strong chess programs like Fritz. She will learn to write poems approaching the same technical excellence as the computer poet. In this way, she achieves a greater understanding and mastery over the mechanical techniques of her art. She may then draw on her human experience, and with the technical competence and self-awareness learned from the machine, become a great poet. To do this, if Dewey is right, she goes beyond the ruminating brain regarded as a closed mechanical system, to the brain as part of the body forming an open system, connected directly with the world. Turing himself put the difference starkly:

The new problem (i.e., the Turing test) has the advantage of drawing a fairly sharp line between the physical and intellectual capacities of a man. No engineer or chemist claims to be able to produce a material which is indistinguishable from the human skin. It is possible that at some time this might be done, but even supposing that this invention available we should feel there was little point in trying to make a 'thinking machine' more human by dressing it up in such artificial flesh. (Turing 1950, p. 434)

Dewey would agree that there is no point in this, but not because living in the world and having flesh is irrelevant to human thinking, but the opposite; because it is essential to being human, and therefore to the thinking and creativity that are part of being human. On this view, Turing's "fairly sharp line" is a mistake that reflects the traditional dualism that Dewey rejected.

At present, according to Dewey's view, to be a human artist we need experience and to have human experience we need flesh. Therefore, if we really believe that machines can be artists (rather than just treat it as a metaphor), we would be changing the meaning of art and artist. This may happen, but it would be a more momentous change than the change Benjamin pointed out, which was the change in the meaning of art and artist when photography and film became assimilated into the category of art. For Dewey, such a change would entail a hardening of the traditional dualist view of what is to be human, and this is what he spent his life resisting

We take this to be a serious matter, but whatever viewpoint we adopt the really exciting prospect for us (as Deweyan), and one of the underlying goals of AI, remains the contribution of computer technology to stimulate, challenge, and provoke artistic practice of all forms. The systems we have been involved in developing and implementing reflect this belief.

\section{A Deweyan Approach to the Design of AI Systems for Creativity}

In recent work, we have tried to take a more Deweyan approach to the design of AI in order to support, challenge and provoke human creative activity. We are interested in designing systems that can support the ongoing moment-to-moment process of content generation over a sustained period of time. The approach has been to start with the musician and design systems based on the way in which they improvise.

One example is the system Reflexive Looper that placed the solo artist at the centre of the design process and enabled them to create new kinds of music performances (Pachet et al. 2013). In a single session (i.e., all the data the system uses about the style of a musician comes from a single performance 
or episode of interaction), and choosing a repeating chord sequence (of a blues or a standard, for example) as the underlying musical canvass, the musician can record themselves playing (say) a bass line (perhaps with different intensities and styles), and then chords (similarly), and then a melody, and then a series of improvisations.

Then, the solo musician can effectively play with musical copies of themselves. For example, by playing chords, the system will generate the "best fitting" bass line and improvised melody. It is important to note that the musical versions offered are not direct recordings of the original performance, rather real-time machine-created and adaptive versions based on elements such as chord or key changes, playing mode or style. The creative success of this system is that it provides a genuine sense of being able to extend the creative range of the musician and a realistic experience of interacting with alternate versions of oneself in a live musical performance.

The machine imparts a significant sense of creative agency by inheriting the output of the creative activity of the human performer with sufficient transformation to not seem like direct imitation. Its musical analyses are based solely on what the musician is doing in the moment of their sustained, ongoing moment-to-moment performance with the system. The creative activity of musicians is challenged, provoked, and stimulated —indeed, often being put considerably out of their natural comfort zone-by leading to musical creations that would not have been possible for a musician playing alone.

Another example is the SpeakeSystem (Yee-King and d'Inverno 2016). SpeakeSystem is a real-time interactive music improviser which takes as its input an audio stream from a monophonic instrument, and it produces at its output a sequence of musical note events which can be used to control a synthesizer to produce performances. The system segments and labels incoming audio from the human musician and constructs a hierarchical Markov model of the label sequence. It labels the segments with their length (after quantization), their type, either "note" or "rest", and the pitch of the note. The system then samples from the model to generate a stream of output labels that are statistically similar to the input sequence.

The BBC Radio 3 Jazz Line Up programme commissioned SpeakeSystem in 2015 for a live human and computer performance with alto saxophone player Martin Speake-one of the UK's leading jazz musicians.

A recording of the performance and the source code for the system is available in an open source repository [104]. The system is the latest in a series, including one judged as one of the "sessions of the year" when it played with flutist Finn Peters in 2009.

Again, the artist had to interact with the system in a moment-to-moment, sustained dialogue which led to genuine moments of musical ingenuity which would simply not have happened without the contribution of the machine. Taking a deliberately Deweyan approach, we actually posed the idea that the only way in which one could make judgments of the quality of the human/machine collaborating was by looking at the experiences of the musician, the audience, and the software engineer, and we used the system Music Circle in order to do this. We believe that this approach is critical in thinking about creative systems and part of our determination as we build more systems.

Whilst our systems are about music improvisation, we believe that they provide the appropriate context to explore human/machine co-creation in that interaction needs to take place in a live, moment-to-moment, embodied, and performative context over a sustained period of time. We are interested in exploring how the human or machine can take different kinds of roles spanning different notions of agency and autonomy (including who is following who) that would naturally unfold in any human/human improvised setting. Other work in this space ranges from the use of gesture analysis systems and enabling the ongoing moment-to-moment interaction of performers of using gesture recognition systems (Zamborlin et al. 2014) where there is almost no system agency up to our most recent attempts to understand the psychological flow state of performers during improvised musical interaction with machines with a great deal of musical agency and autonomy (McCormack et al. 2019).

Although the focus is mainly on music and improvisation, we believe that this space provides us with exactly the right setting in order to consider the scientific challenges of building systems that 
generate creative content and builds upon proposals we made in a recent paper that come through a deeper investigation in what we mean when we talk about creativity (Still and d'Inverno 2016).

Author Contributions: Conceptualisation and narrative design, A.S. and M.d.; original draft preparation, Sections 1-8 A.S. lead, Section 9 M.d. lead; overall writing, review and editing, A.S. and M.d.

Funding: This research received was not supported by external funding.

Conflicts of Interest: The authors declare no conflict of interest.

\section{References}

Ariza, Christopher. 2009. The interrogator as critic: The Turing test and the evaluation of generative music systems. Computer Music Journal 33: 48-70. [CrossRef]

Arnold, Matthew. 1914. Essays by Matthew Arnold. London: Oxford University Press.

Benjamin, Walter. 1968. The work of art in the age of mechanical reproduction. In Illuminations. London: Fontana, pp. 214-18. First published 1937.

Boden, Margaret A. 1990. The Creative Mind: Myths and Mechanisms. London: Weidenfeld \& Nicolson.

Boden, Margaret A. 2009. Computer models of creativity. AI Magazine Fall 30: 23-39. [CrossRef]

Boden, Margaret A. 2010. The Turing test and artistic creativity. Kybernetes 39: 409-13. [CrossRef]

Claxton, Guy. 2006. Cultivating creative mentalities: A framework for education. Thinking Skills and Creativity 1: 57-61. [CrossRef]

Colton, Simon. 2008. Creativity Versus the Perception of Creativity in Computational Systems. Paper presented at the AAAI Spring Symposium: Creative Intelligent Systems, Palo Alto, CA, USA, March 26-28.

Colton, Simon. 2012. The Painting Fool: Stories from Building an Automated Painter. In Computers and Creativity. Edited by McCormack Jon and Mark d'Inverno. Berlin: Springer.

Cook, Gary A. 1979. Whitehead's Influence on the Thought of G. H. Mead. Transactions of the Charles S. Peirce Society 15: 107-31.

Dewey, John. 1934. Art as Experience. New York: Perigree Books.

Dewey, John. 1948. Foreward. In The Unfolding of Artistic Activity. Edited by Henry Schaefer-Simmern. Berkeley: University of California Press.

Dewey, John. 1989. William James and the world today. In The Later Works of John Dewey, 1925-1953: Essays, Reviews, and Miscellany, 1942-1948. Edited by Jo Ann Boydston. Carbonville: Southern Illinois University Press. First published 1942.

Dewey, John, Boyd Henry Bode, Horace Meyer Kallen, Addison Webster Moore, Harold Chapman Brown, George Herbert Mead, and Henry Waldgrave Stuart. 1917. Creative Intelligence; Essays in the Pragmatic Attitude. New York: Henry Holt.

Eigemmal, Ahmed, Bingchen Liu, Mohamed Elhoseiny, and Marian Mazzone. 2017. CAN: Creative Adversarial Networks Generating "Art" by Learning about Styles and Deviating from Style Norms. arXiv, arXiv:1706.07068.

Emerson, Ralph. W. 1975. The American Scholar. In The Portable Emerson. Edited by MarkVan Doren. Harmondsworth, Middlesex: Penguin Books, pp. 23-46.

Glăveanu, Vlad. 2010. Paradigms in the study of creativity: Introducing the perspective of cultural psychology. New Directions in Psychology 28: 79-93. [CrossRef]

Guilford, John P. 1939. General Psychology. Princeton: Van Nostrand.

Guilford, John P. 1950. Creativity. American Psychologist 5: 444-54. [CrossRef] [PubMed]

Hennessey, Beth A., and Teresa M. Amabile. 2010. Creativity. Annual Review of Psychology 61: 569-98. [CrossRef] [PubMed]

Hutton, Charles. 1811. A Course of Mathematics. London: F.C. and J. Rivington.

Johnston, James S. 2006. Inquiry and Education: John Dewey and the Quest for Democracy. Albany: State University of New York Press.

Kasparov, Gary. 2010. The Chess Master and the Computer. New York Review of Books, February 11.

Kasparov, Gary. 2018. Deep Thinking: Where Machine Intelligence Ends and Human Creativity Begins. London: John Murray. Levitt, Theodor. 1963. Creativity Is Not Enough. Harvard Business Review, August.

Mackintosh, Nicholas. J. 2011. IQ and Human Intelligence. Oxford: Oxford University Press. 
McCormack, Jon, Gifford Toby, Hutchings Patrick, Llano Maria Teresa, Matthew Yee-King, and Mark d'Inverno. 2019. In a Silent Way Communication between AI and improvising musicians beyond sound. Paper presented at CHI 2019 Conference on Human Factors in Computing Systems, Glasgow, UK, May 4-9.

Maslow, Abraham H. 2000. The Maslow Business Reade. New York: Wiley. First published 1959.

Mazzone, Marian, and Ahmed Eigemmal. 2019. Art, creativity, and the potential of Artificial Intelligence. Arts 8: 26. [CrossRef]

Osborn, Alex F. 1948. Your Creative Power: How to Use Imagination. New York: Scribners.

Pachet, François, Pierre Roy, Julien Moreira, and Mark d'Inverno. 2013. Reflexive loopers for solo musical improvisation. In Proceedings of the SIGCHI Conference on Human Factors in Computing Systems. New York: ACM, pp. 2205-208.

Ribot, Th. 1906. Essay on the Creative Imagination. London: Kegan Paul, Trench, Trubner \& Co., Ltd.

Rudolph, John L. 2014. Dewey's “Science as Method” a Century Later. Reviving Science Education for Civic Ends. American Educational Research Journal 51: 1058-83. [CrossRef]

Schaeffer-Simmern, Henry. 1948. The Unfolding of Artistic Activity. Berkeley: University of California Press.

Silver, David, Julian Schrittwieser, Karen Simonyan, Ioannis Antonoglou, Aja Huang, Arthur Guez, Thomas Hubert, Lucas Baker, Matthew Lai, Adrian Bolton, and et al. 2018. A general reinforcement learning algorithm that masters chess, Shogi, and Go through self-play. Science 262: 1140-44. [CrossRef] [PubMed]

Simon, Herbert A. 1995. Explaining the ineffable: Al on the topics of intuition, insight and inspiration. In Fourteenth International Joint Conference on Artificial Intelligence. San Francisco: Morgan Kaufmann, pp. 939-48.

Stein, Morris I. 1953. Creativity and culture. Journal of Psychology 36: 311-22. [CrossRef]

Still, Arthur. 1986. The biology of science: An essay on the evolution of representational cognitivism. Journal for the Theory of Social Behaviour 16: 257-68. [CrossRef]

Still, Arthur, and Mark d'Inverno. 2016. A history of creativity for future AI research. Paper presented at 7th International Conference on Computational Creativity (ICCC 2016), Universite Pierre et Marie Curie, Paris, France, June 27-July 1.

Sturm, Bob L., and Oded Ben-Tal. 2017. Back to music practice: The evaluation of deep learning approaches to music transcription, modelling and generation. Journal of Creative Music Systems 2: 1. [CrossRef]

Turing, Alan M. 1950. Computing Machinery and Intelligence. Mind 59: 433-60. [CrossRef]

Varela, Francisco, Evan Thompson, and Eleanor Rosch. 1991. The Embodied Mind: Cognitive Science and Human Experience. Cambridge: MIT Press.

Wagstaff, Kiri L. 2012. Machine Learning that Matters. Paper presented at 29th International Conference on Machine Learning, Edinburgh, Scotland, UK, June 26-July 1.

Whitehead, Alfred N. 1968. Process and Reality. New York: The Free Press. First published 1929.

Wiggins, Gareth A. 2008. Computer Models of Musical Creativity: Literary and Linguistic Computing. Literary and Linguistic Computing 23: 109-16. [CrossRef]

Yee-King, Matthew, and Mark d'Inverno. 2016. Experience driven design of creative systems. Paper presented at 7th International Conference on Computational Creativity (ICCC 2016), Universite Pierre et Marie Curie, Paris, France, June 27-July 1.

Zamborlin, Bruno, Frédéric Bevilacqua, Marco Gillies, and Mark d'Inverno. 2014. Fluid gesture interaction design applications of continuous recognition for the design of modern gestural interfaces. ACM Transactions on Interactive Intelligent Systems 3: 30-45. [CrossRef]

(C) 2019 by the authors. Licensee MDPI, Basel, Switzerland. This article is an open access article distributed under the terms and conditions of the Creative Commons Attribution (CC BY) license (http://creativecommons.org/licenses/by/4.0/). 